\title{
Growth peculiarities of doped lithium dihydrogen phosphate single crystals from nonstoichiometric solution
}

\author{
A.N.Iurchenko $^{1}$, A.P.Voronov ${ }^{1}$, A.D.Roshal $^{2}$, \\ S.I.Kryvonogov ${ }^{1}$, G.N.Babenko ${ }^{1}$, I.M.Pritula ${ }^{1}$ \\ ${ }^{1}$ Institute for Single Crystals, STC"Institute for Single Crystals", \\ National Academy of Sciences of Ukraine, \\ 60 Nauky Ave, 61001 Kharkiv, Ukraine \\ ${ }^{2}$ V.Karazin Kharkiv National University, 4 Svobody Sq., \\ 61002 Kharkiv, Ukraine
}

\section{Received February 22, 2017}

\begin{abstract}
Single crystals of lithium dihydrogen phosphate (LDP) have been grown on a seed by pulling-out from aqueous viscous solutions with an excess of orthophosphoric acid. The effect of solution stoichiometry on the habit and morphology of the faces of LDP single crystals is investigated. It is established that the habit of the crystals changes with the rise of concentration of the acid in the solution. Shown is the effect of dopants of thallium ions, molecules of salicylic and 5-aminosalicylic acid on the morphology of the crystal faces, which manifests itself in a diminution of the width of the terraces and an increase of the density of the growth steps. Proposed is a model of arrangement of the dopant molecules in the interplanar space of LDP crystal lattice.

Keywords: lithium dihydrogen phosphate, crystal growth, oriented crystal, doped crystal, fluorescence anisotropy, intramolecular proton transfer, ESIPT, thermal neutron capture, salicylic acid.
\end{abstract}

Монокристаллы дигидрофосфата лития (LDP) выращивали из водных растворов с избытком ортофосфорной кислоты вытягиванием на затравку. Изучено влияние стехиометрии раствора на габитус и морфологию граней LDP. Показано влияние легирующих добавок ионов таллия, молекул салициловой и 5-аминосалициловой кислот на морфологию граней кристалла, что проявляется в уменьшении ширины террас и возрастании плотности ступеней роста. Предложена модель расположения молекул в межплоскостном пространстве кристаллической решетки LDP.

Особливості вирощування допованих монокристалів літій дигідрофосфату з нестехіометричного розчину. А.М.Юрченко, О.П.Воронов, О.Д.Рошаль, С.І.Кривоногов, Г.М.Бабенко, І.М.Притула.

Монокристали літій дигідрофосфату (LDP) вирощували з водних розчинів із надлишком ортофосфорної кислоти витягуванням на затравку. Вивчено вплив стехіометрії розчину на габітус та морфологію граней LDP. Показано вплив легуючих домішок йонів талію, молекул саліцилової та 5-аміносаліцилової кислот на морфологію граней кристала, що виявляє себе у зменшенні ширини терас та зростанні щільності ступеней росту. Запропоновано модель розташування молекул у міжплощинному просторі кристалічної гратки LDP. 


\section{Introduction}

Lithium dihydrogen phosphate single crystals $\mathrm{LiH}_{2} \mathrm{PO}_{4}$ (LDP) belong to the group of alkali metal dihydrogen phosphates (KDP group [1,2]: $\mathrm{MH}_{2} \mathrm{RO}_{4}$, where $\mathrm{M}=\mathrm{Li}$, $\mathrm{K}, \mathrm{Rb}, \mathrm{Cs}, \mathrm{NH}_{4} ; \mathrm{R}=\mathrm{P}, \mathrm{As}$ ). Among these crystals, LDP is distinguished by its crystalline structure, physical properties, and crystallization conditions [3-5]. LDP crystallizes in the orthorhombic crystal system, the symmetry class Pna 2 , with the lattice parameters $a=6.241 \AA, \quad b=7.643 \AA, \quad c=$ $6.870 \AA, Z=4$, and possesses piezoelectric properties [6]. In water at a temperature higher than $20^{\circ} \mathrm{C}$, it dissolves incongruently [5] that is due to the shift of the equilibrium at dissolution in the direction of the formation of insoluble lithium phosphate $\mathrm{Li}_{3} \mathrm{PO}_{4}$. As known from the literature, single crystals of LDP were grown from nonstoichiometric solutions with excess of $\mathrm{H}_{3} \mathrm{PO}_{4}$, both by the method of solvent evaporation at $40^{\circ} \mathrm{C}[3,7]$, and by the method of temperature lowering in the interval of $70-40^{\circ} \mathrm{C}$ [5]. The excess of $\mathrm{H}_{3} \mathrm{PO}_{4}$ on the level of $30 \mathrm{wt}$. \% shifts the equilibrium toward the formation of $\mathrm{LiH}_{2} \mathrm{PO}_{4}$ according to the Le Chatelier principle.

K.S.Lee et al. [7] calculated the habit of LDP crystals with the planes corresponding to the space group Pna $2_{1}-\mathrm{C}^{9}{ }_{2 v}$ with indications of the Miller indices of all the faces bounding a closed form. Altogether, there are 19 faces and 32 angles: the pyramid $\{111\},\{111\}$; the prism $\{110\}$; the dome $\{011\} ;\{01 I\} ;\{20 T\}$; the pedestal $\{00 I\}$. The face $(001)$ does not appear at all owing to the presence of the polar axis 21 parallel to the [001] direction.

In [8], we found that the increase in the excess of $\mathrm{H}_{3} \mathrm{PO}_{4}$ in LDP solution from $20 \%$ to $75 \%$ led to the change in the crystal habit from the full shape to the habit represented by the faces of the pyramid $\{111\}$ : (111), $(1 \overline{1}),(1 \overline{1} 1),(\overline{11} 1)$ with the pedestal face $(00 \mathrm{i})$ occupying virtually the whole of the prism area $\{110\}$. The crystal is shaped as a tetrahedral pyramid.

In the present study, we have continued to investigate the effect of an excess of orthophosphoric acid and the dopant additives in the solution on the habit and morphology of the surface of the faces of LDP crystals. Simulation of the shape of crystals is performed depending on the relative growth rate of the faces. The projections of the crystal lattice on the crystal face are calculated. Proposed is a model for the loca-

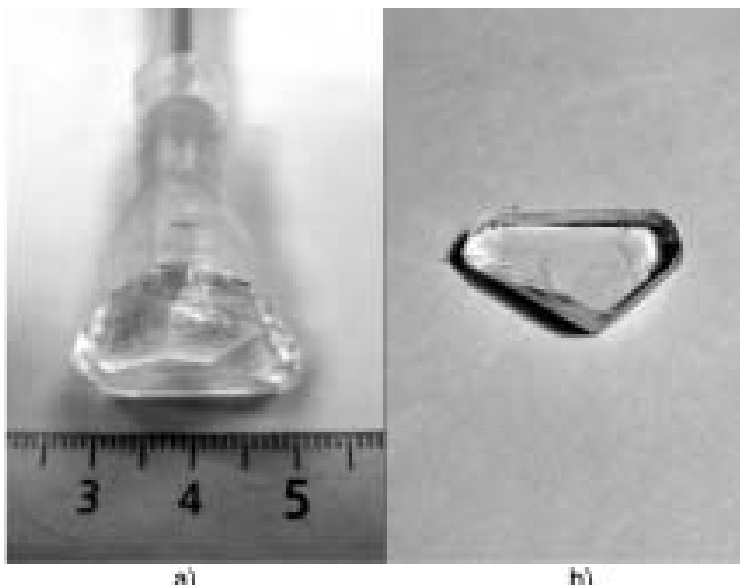

a)

b)

Fig. 1. a) LDP crystal grown on (110) oriented seed by pulling-out from solution; b) polished crystal plate.

tion of salicylic acid molecules in the interplanar space of the LDP crystal lattice.

\section{Materials and methods}

$\mathrm{LiH}_{2} \mathrm{PO}_{4}$ salt was prepared from high-purity lithium carbonate $\mathrm{Li}_{2} \mathrm{CO}_{3}$ and $85 \%$ orthophosphoric acid. The obtained powder was filtered and dried. LDP single crystals were grown by the method of solvent evaporation from non-stoichiometric aqueous solutions based on $20 ; 30 ; 40 ; 50 ; 60 ; 75$ and 85 wt. $\%$ of $\mathrm{H}_{3} \mathrm{PO}_{4}$.

The crystals doped with thallium ions, salicylic acid and 5-aminosalicylic acid were grown by pulling-out from aqueous viscous solutions on the (110) oriented seed (Fig. 1). This new approach to the growth of lithium dihydrogen phosphate crystals from viscous aqueous acid solutions is based on a combination of the classical conditions for the growth of crystals from the solution with the melt growth technique (the Czochralski method), the so-called modified top-seeded solution growth (MTSSG) method. In the process of growth, the crystals were faceted along the end sides with natural faces: the ends of the triangular crystal plate were faceted with ( $\overline{1} 11),(\overline{1} 1 \overline{1})$ and $(1 \overline{1} 0)$ faces (Fig. 1b).

The surface of the crystal faces was examined using an optical microscope Axioskop $40 \mathrm{~A}$ Pol in reflected light with $100^{\times}$and $500^{\times}$zoom, and atomic force microscope NT-MDT in the contact mode.

The crystal habit was calculated by means of the WinXMorph program [9], the projections of the crystal lattice on the crystal face were obtained using the Crystal Maker program [10]. 


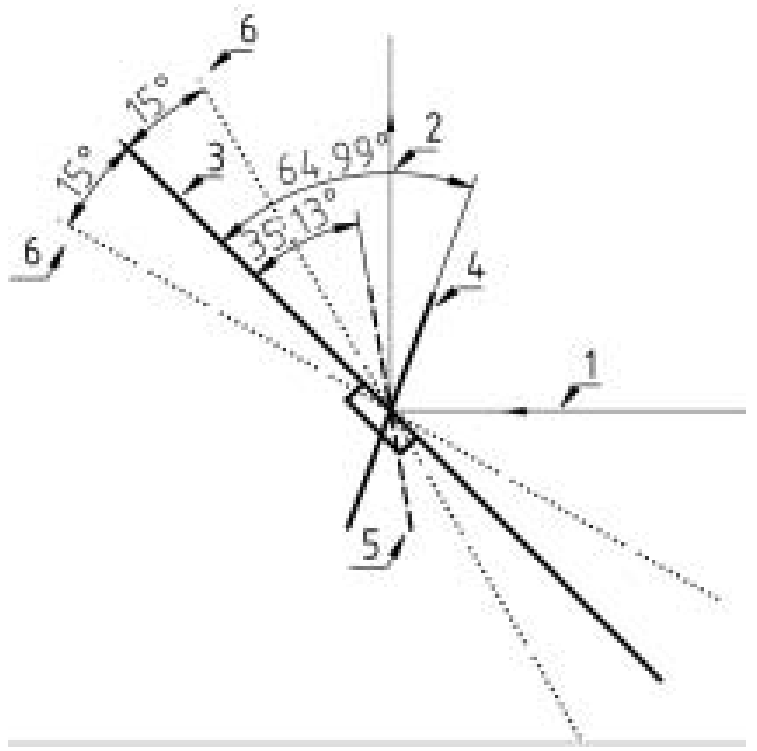

Fig. 2. Scheme for recording the fluorescence anisotropy spectra of the LDP crystal oriented by (110) face when rotating about the vertical axis: 1 - excitation beam; 2 - beam directed to the photodetector; 3 - initial position of the crystal; 4,5 - location of salicylic acid derivatives relative to (110) face; 6 - rotation of the crystal, at which the interaction of the exciting beam with the derivatives of salicylic acid is maximal.

The optical absorption and photoluminescence spectra of the doped LDP crystals were measured with a spectrophotometer Lambda 35, Perkin Elmer and a fluorescence spectrophotometer Cary Eclipse, Varian in the interval of 190-600 $\mathrm{nm}$.

To register the fluorescence spectra of the doped LDP crystals, the oriented crystal plates were fixed vertically on a special holder at an angle of $45^{\circ}$ to the exciting beam. The vertical rotation axis lay in the plane (110) of the crystal plate and perpendicular to the plane $(1 \overline{1} 0)$. The horizontal rotation axis was perpendicular to the plane (110). The fluorescence anisotropy spectra were recorded when the crystal was rotated about the vertical axis [1 $1 \overline{1} 0]$ by $\pm 25^{\circ}$ clockwise and counterclockwise relative to the initial position of the crystal (Fig. 2), and then about the horizontal axis [110] by $\pm 35^{\circ}$ clockwise and counterclockwise with respect to the initial position (Fig. 3).

The sensitivity of LDP crystals to thermal neutrons from $\mathrm{Pu}-\mathrm{Be}$ source was evaluated using a Hamamatsu R7056 PMT and a multichannel pulse analyzer. The sample was placed on $\mathrm{Nal}(\mathrm{TI}) \alpha$-detector. The lower detection threshold was $5 \mathrm{keV}$ in $\mathrm{Nal}(\mathrm{TI})$ scale.

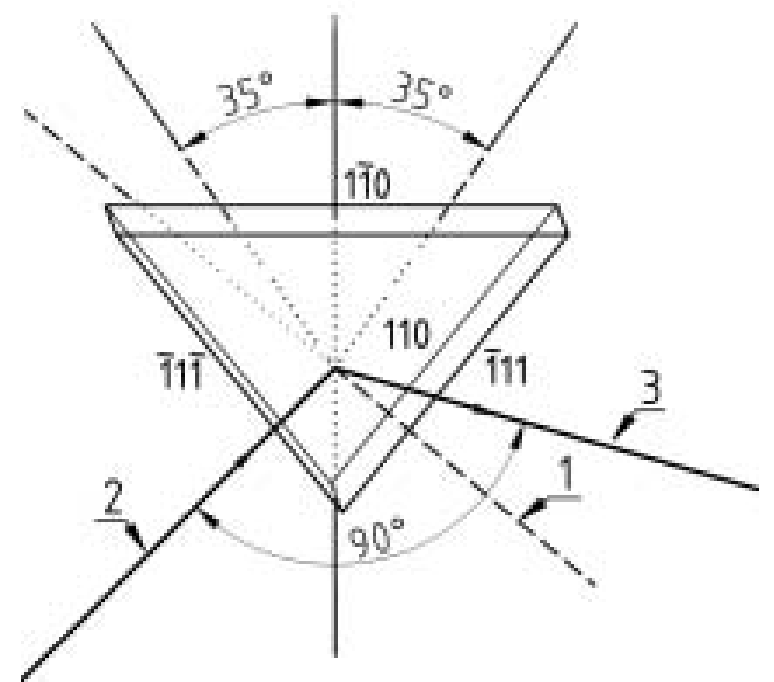

Fig. 3. Scheme for recording the fluorescence anisotropy spectra of LDP crystal oriented by (110) face when rotating about the horizontal axis: 1 - horizontal axis of rotation; $2-$ excitation beam; 3 - beam directed to the photodetector.

The concentration of salicylic acid in the crystal was measured by the photoluminescence method, the concentration of thallium ions was determined by the method of inversion voltammetry.

\section{Results and discussion}

Effect of solution stoichiometry on habit and morphology of LDP faces

The crystal habit is defined by the parameters of crystal growth from the solution (temperature, supersaturation, solution $\mathrm{pH}$, presence of impurities and hydrodynamics). In this study, the main parameter affecting the habit of LDP crystals was the stoichiometry of the solution (solution $\mathrm{pH}$ ) as a consequence of the change in the concentration of $\mathrm{H}_{3} \mathrm{PO}_{4}$ in the solution. The rest of the growth parameters were fixed.

As mentioned above [8], the excess of $\mathrm{H}_{3} \mathrm{PO}_{4}$ leads to changes in the crystal habit from the full shape to a tetrahedral pyramid. According to the Curie-Wulf rule, the faces with the lowest growth rates are the most developed. Thus, from the increasing the area of the face or its distance from the center of the crystal, one can estimate the growth rate of this face relative to other faces. In order to trace the tendency of the relative growth rates of LDP crystal faces to change with the stoichiometry of the solution, we performed model calculations of the crystal habit variants, setting a differ- 

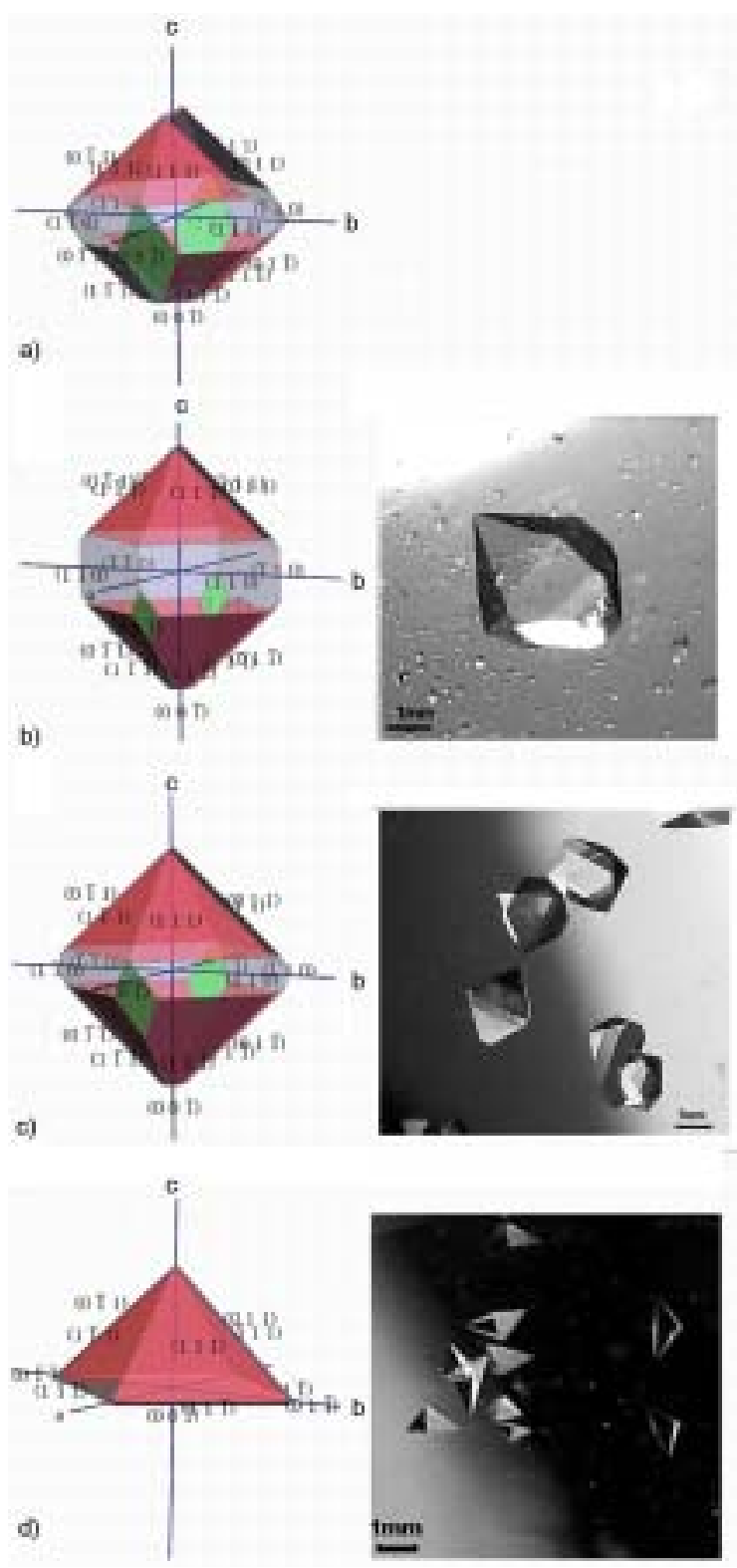

Fig. 4. Model variants of habit of LDP crystal: a) with equal distances between the faces and the center of the crystal; b) grown from $20 \% \mathrm{H}_{3} \mathrm{PO}_{4}$; c) $33 \% \mathrm{H}_{3} \mathrm{PO}_{4}$; d) $75 \% \mathrm{H}_{3} \mathrm{PO}_{4}$ solutions (microphotographs taken from [8]).

ent distance of the faces from the center of the crystal. The initial calculation conditions are presented in Table 1.

Since the distances from the center of the crystal to the faces are proportional to the growth rate of the faces, the values of these distances can be considered as the values of the relative growth rates of the faces. Fig. 4 shows the habit variants for LDP crystals. Fig. 4a corresponds to the case with equal distances between the faces and the center of the crystal, as well as similar to the habit of the crystals grown
Table 1. Distance between the faces and the center of the crystal in various variants of model calculations of the LDP crystal habit.

\begin{tabular}{|c|c|c|c|c|}
\hline \multicolumn{5}{|c|}{ Distance between face and crystal centre } \\
\hline Face & a & b & c & d \\
\hline 111 & 1 & 1 & 1 & 1 \\
\hline $1 \overline{1} 1$ & 1 & 1 & 1 & 1 \\
\hline $11 \overline{1}$ & 1 & 1 & 1 & 1 \\
\hline 110 & 1 & 1.05 & 0.9 & 1.3 \\
\hline 011 & 1 & 1.2 & 1.2 & 1.25 \\
\hline $01 \overline{1}$ & 1 & 1.2 & 1.2 & 1.25 \\
\hline $20 \overline{1}$ & 1 & 1.1 & 1.1 & 1.5 \\
\hline $\begin{array}{lll}0 & 0 & \overline{1}\end{array}$ & 1 & 1.5 & 1.5 & 0 \\
\hline
\end{tabular}
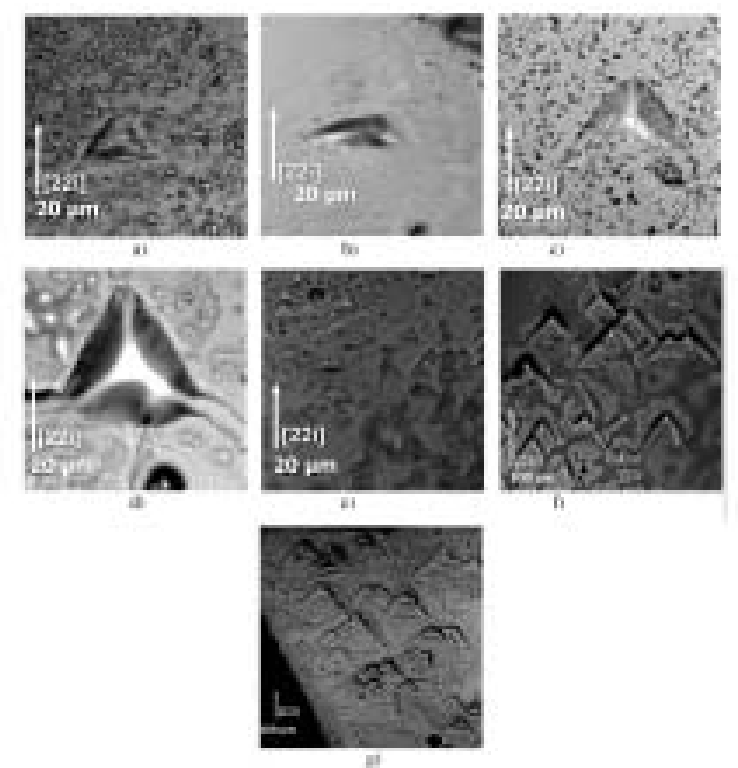

Fig. 5. Microphotographs of growth hillocks on $\{111\}$ faces of LDP crystals grown from the solutions based on a) $20 \%$, b) $30 \%$, c) $40 \%$, d) $50 \%$, e) $60 \%$, f) $75 \%$, and g) $85 \% \mathrm{H}_{3} \mathrm{PO}_{4}$.

from the solutions based on $20 \% \mathrm{H}_{3} \mathrm{PO}_{4}$ (Fig. 4b), $33 \% \mathrm{H}_{3} \mathrm{PO}_{4}$ (Fig. 4c) and $75 \%$ $\mathrm{H}_{3} \mathrm{PO}_{4}$ (Fig. 4d). For comparison, microphotographs of the crystals are shown in the same figure: LDP crystals grown from $20 \%$ $\mathrm{H}_{3} \mathrm{PO}_{4}$ are faceted with all the planes represented by the full shape; the ones grown from $33 \% \mathrm{H}_{3} \mathrm{PO}_{4}$, prism face $\{110\}$ are developing to a lesser extent and occupy a smaller area, that testifies to an increase in the relative growth rate of these faces. The crystal grown from $75 \% \mathrm{H}_{3} \mathrm{PO}_{4}$ is a pyramid with a tetrahedral base, where a sharp 


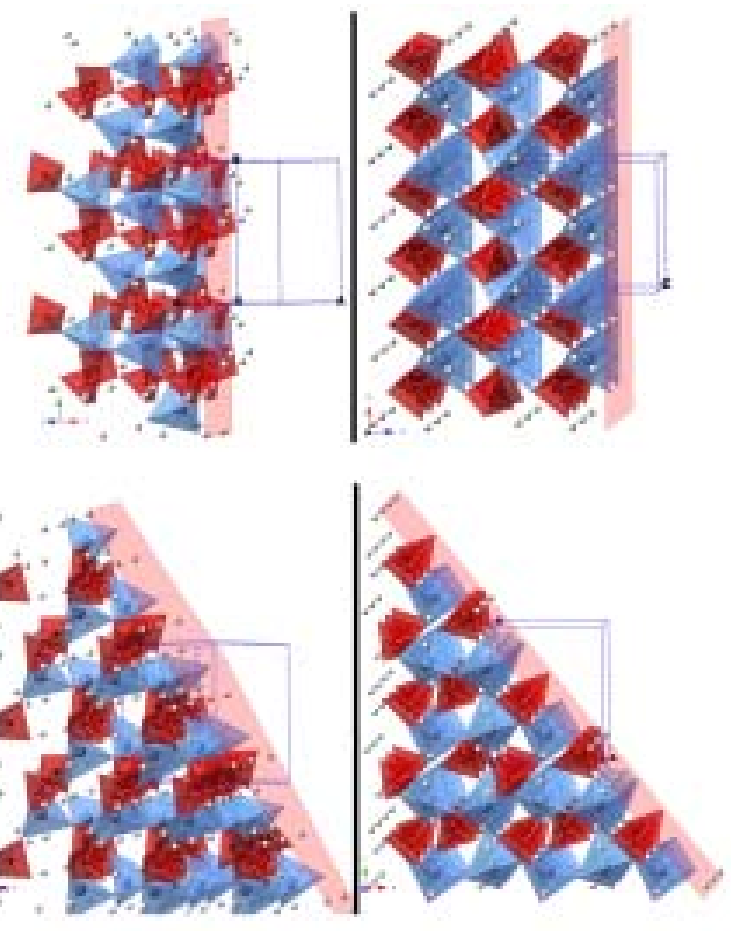

Fig. 6. The projections of LDP crystal lattice on

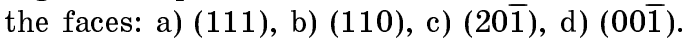

decrease in the relative growth rate of the pedestal edge $(00 \overline{1})$ is observed, and the face $(00 \overline{1})$ occupies virtually the entire $\{110\}$ prism area. Our simulation has shown that the faces of the prism $\{110\}$, the dome $\{011\},\{01 \overline{1}\},\{20 \overline{1}\}$ increase the growth rate relative to the edge of the pyramid $\{111\}$ with an increase in excess of phosphoric acid in the solution, and the growth of the $(00 \overline{1})$ face is suppressed.

The study of the faces of LDP crystals revealed the effect of the concentration of orthophosphoric acid on the morphology of the faces surface. Fig. 5 shows photomicrographs of growth hillocks of the pyramidal faces $\{111\}$ of the crystals grown from the solutions with different stoichiometry. The slopes of the growth hillocks, symmetrical at a minimum concentration of the acid in the solution, change as the acid concentration rises. One of the slopes flattens, while the other two become much steeper, which points to an increase in the face growth rate.

To establish the origin of the change in the relative growth rate of LDP crystal faces with a change in the concentration of orthophosphoric acid, there was calculated the lattice of the crystal with cuts parallel to the $\{111\},\{110\},\{20 \overline{1}\}$ and $(00 \overline{1})$ faces (Fig. 6). While considering the charge state of the growing planes, it can be concluded that the planes of the pyramid $\{111\},\{11 \overline{1}\}$, the prism $\{110\}$, as well as the dome $\{011\}$, $\{01 \overline{1}\}$ and $\{20 \overline{1}\}$ terminate with alternating rows of $\mathrm{LiO}_{4}$ tetrahedrons and $\mathrm{H}_{2} \mathrm{PO}_{4}^{-}$anions; the surface of the face in this case remains neutral. The pedestal face $\{00 \vec{i}\}$ is terminated with either $\mathrm{H}_{2} \mathrm{PO}_{4}{ }^{-}$anions or the $\mathrm{LiO}_{4}$ tetrahedrons, so the face surface is charged either negatively or positively, easily annexing the dihydrogen-phosphate anions and lithium cations.

The effect of the solution $\mathrm{pH}$ on the habit of potassium and ammonium dihydrogen phosphate crystals was noted in various studies [11-13]. The modern interpretation of the effect of the solution $\mathrm{pH}$ on the growth of KDP and ADP crystals is based on the model which describes the formation of dimers of dihydrogen phosphate anions $\left(\mathrm{H}_{2} \mathrm{PO}_{4}^{-}\right)_{2}$. There are known the domains of existence for various forms of orthophosphoric acid depending on the acidity of the medium [14]. Depending on the solution $\mathrm{pH}$, $\mathrm{H}_{3} \mathrm{PO}_{4}$ may exist as different molecular or ionic particles, such as: $\mathrm{H}_{3} \mathrm{PO}_{4}, \mathrm{H}_{2} \mathrm{PO}_{4}^{-}$, $\mathrm{HPO}_{4}{ }^{2-}, \mathrm{PO}_{4}{ }^{3-}$. In strongly alkaline solutions $(\mathrm{pH}>12.3)$, the predominating chemical form is orthophosphate anions $\mathrm{PO}_{4}{ }^{3-}$. As the acidity of the medium increases, the phosphate ions are protonated. In the region of predominance of dihydrogen phosphate anions, the latter tend to form dimers.

If $\mathrm{H}_{2} \mathrm{PO}_{4}^{-}$monomers predominate in the solution, then during the integration of $\mathrm{H}_{2} \mathrm{PO}_{4}{ }^{-}$into the crystal lattice, some hydrogen bonds with water molecules break easily enough. In the case when the dimers $\left(\mathrm{H}_{2} \mathrm{PO}_{4}^{-}\right)_{2}$ predominate in the solution, for their integration into the crystal lattice it is also necessary to break the stronger intermolecular hydrogen bonds which form the dimer. As known for KDP crystals [12], the crystal habit calculated without taking into account the possibility of the formation of $\left(\mathrm{H}_{2} \mathrm{PO}_{4}^{-}\right)_{2}$ dimers, is represented by a more complete development of all the faces than the one calculated in the case of predominance of these dimers. It can be assumed that predominance of the dimers of dihydrogen phosphate anion in the solution inhibits the growth of the faces.

Since LDP solution is characterized by an excess of orthophosphoric acid, and a very low $(\leq 0.7$ [8]) solution $\mathrm{pH}$, it contains undissociated molecules of orthophosphoric acid and dimers of dihydrogen phosphate anion. As the acid concentration rises, the bond between the monomers strengthens due to the rise in the degree of association 


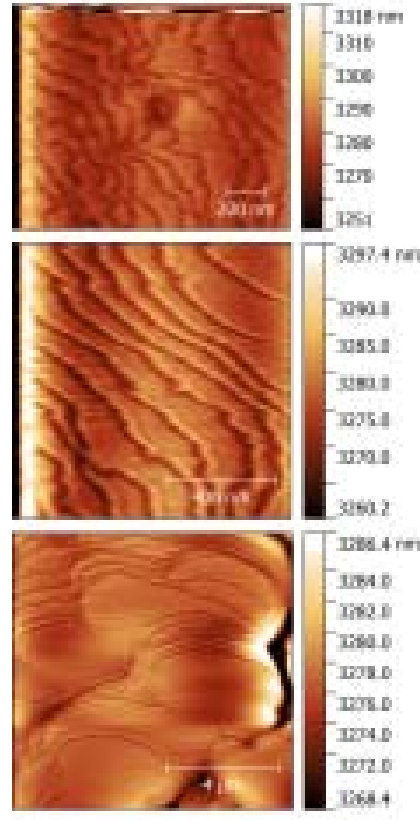

a)
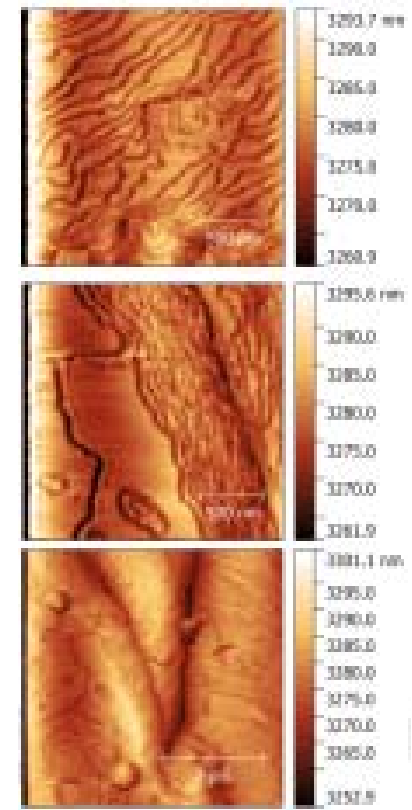

c)
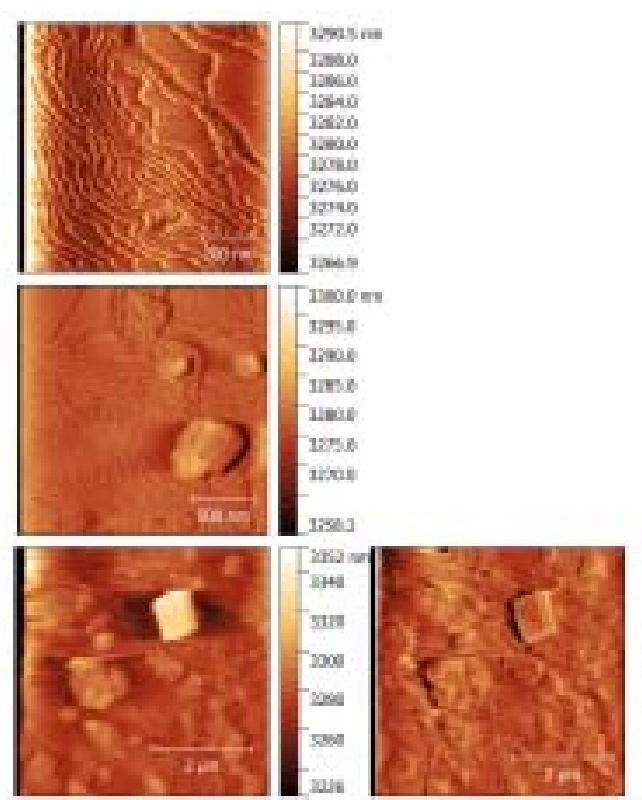

b)
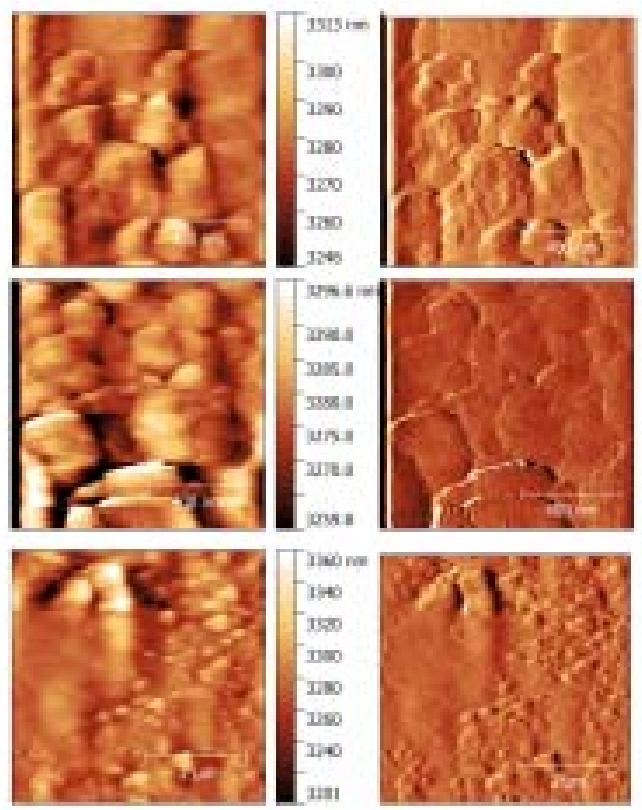

d)

Fig. 7. AFM-images of growth steps of (110) face surface of: a) LDP, b) LDP: $\mathrm{H}_{2} \mathrm{Sal}$, c) LDP: $\mathrm{NH}_{2} \mathrm{Sal}$, d) LDP:TI crystal (for convenience, DFL-images are presented on the right).

of the dihydrogen phosphate anions in the solution. The $\{111\},\{110\}$ and $\{20 \overline{1}\}$ faces, terminating with alternating rows of $\mathrm{LiO}_{4}$ tetrahedrons and $\mathrm{H}_{2} \mathrm{PO}_{4}^{-}$anions, possess local polarity. Due to this, the dissociation probability for dimers of dihydrogen phosphate anions during incorporation into the lattice increases. The $(00 \overline{1})$ face is limited by the layers with one certain type of charge, and does not possess such a property. The dimers and molecules of orthophosphoric acid practically do not embed in the $(00 \overline{1})$ face, and sterically hamper access to the face surface, accumulating in the near-surface layer. In particular, with the predominance of orthophosphoric acid molecules in the solution, the growth of the $(00 \overline{1})$ face is strongly suppressed, and only the 

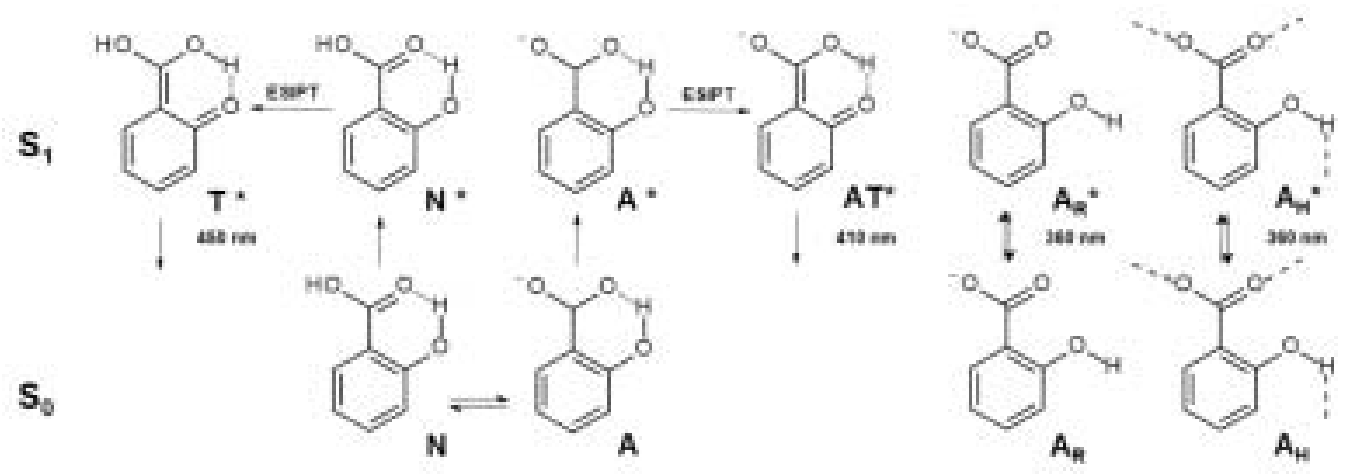

Fig. 8. Scheme of interconversion of protolytic forms of salicylic acid in LDP crystals in the ground and excited states. $\mathrm{N}\left(\mathrm{N}^{*}\right)-$ neutral form of salicylic acid $\left(\mathrm{H}_{2} \mathrm{Sal}\right)$, $\mathrm{T}^{*}-$ salicylic acid phototautomer; $\mathrm{A}\left(\mathrm{A}^{*}\right)$ - salicylate anion $\left(\mathrm{HSal}^{-}\right) ; \mathrm{AT}^{*}-$ salicylate anion-tautomer; $\mathrm{A}_{\mathrm{R}}\left(\mathrm{A}_{\mathrm{R}}^{*}\right)-$ rotamer of the salicylate anion without intramolecular hydrogen bonds; $A_{H}\left(A_{H}^{*}\right)$ - salicylate anion with intermolecular hydrogen bonds.

pyramidal faces $\{11 \overline{1}\}$ grow. Another important factor, which slow down crystal growth, is the increase of the solution viscosity with a decrease in $\mathrm{pH}[15]$.

Influence of the solution impurity composition on LDP crystal surface morphology.

LDP crystals contain a lithium ion in the crystal lattice as a neutron capture agent. When this ion is replaced by a ${ }^{6} \mathrm{Li}$ isotope, the crystals may acquire the properties of a thermal neutron converter [16]. The introduction of activating impurities, which luminescence band is located in the visible spectral range, into the crystal can be used while creating a scintillation material sensitive to thermal neutrons.

In the present work, we studied the effect of organic impurities of salicylic acid, its 5-aminosalicylic acid derivative and inorganic impurity of monovalent thallium on the morphology of the surface of crystal faces. The choice of doping organic additives was based on the fact that flat organic molecules can be incorporated in KDP and ADP crystals in the interplanar space of the crystal lattice [17]. Since LDP crystals were grown from phosphate solutions, the dopants were chosen among planar molecules capable of fluorescence and soluble in a very acidic aqueous medium. Salicylic and 5 -aminosalicylic acids meet these requirements. Thallium ions are widely known activators in alkali-halide scintillators.

Impurities of salicylic acid, 5-aminosalicylic acid and thallium ions (in the form of thallium nitrate) were introduced into the growth solution at a concentration of 0.02 , 0.1 and 1.0 wt. $\%$ to the weight of the dissolved LDP, respectively. The concentration of salicylic acid and thallium in the crystal were $5 \cdot 10^{-4}$ wt. $\%$ and $3.9 \cdot 10^{-3}$ wt. $\%$, correspondingly. Figure 1 shows the appearance of LDP crystal grown by pulling-out from the solution. The crystal was cut into plates; the morphology of the surface of the freshly grown face (110) was studied ex situ using an atomic force microscope. The obtained AFM-images of the surface of the faces are presented in Fig. 7.

The AFM-image of the (110) face surface of undoped LDP crystal (Fig. 7a) points to a layered-spiral growth mechanism [18]. The influence of the admixture of salicylic acid (Fig. 7b) manifests itself in a decrease in the width of the terraces and an increase in the density of the growth steps. 5-aminosalicylic acid (Fig. 7c) also reduces the width of the terraces and increases the density of the growth steps, but to a lesser extent. The estimated height of the growth steps is $100-200 \AA$, which allows assuming advance of the macrosteps.

The effect of organic molecules on the crystal growth may be explained by stereochemical interaction of salicylate anions with the growing face. We calculated the projections of the crystal lattice of LDP on the $\{111\},\{110\},\{20 \bar{T}\}$ and $(00 \overline{1})$ faces of the crystal (Fig. 6). As is seen, the (110) plane is terminated with alternating rows of $\mathrm{LiO}_{4}$ tetrahedrons (in fact $\mathrm{Li}^{+}$cations) and $\mathrm{H}_{2} \mathrm{PO}_{4}{ }^{-}$anions. Although the surface of the face remains neutral in this case, due to compensation of the charges between the adjacent rows of the groups of atoms, there may arise a local ion-dipole interaction between crystal lattice and salicylic acid molecules is possible. The molecules are located on the terraces and block the advance of the 
Table 2. Spectrophotometric properties of LDP: $\mathrm{H}_{2}$ Sal crystals

\begin{tabular}{||c|c|c||}
\hline \hline$\lambda_{e x}, \mathrm{~nm}$ & $\lambda_{e m}, \mathrm{~nm}$ & Stokes shift, $\mathrm{cm}^{-1}$ \\
\hline \multirow{2}{*}{305} & 360 & 5000 \\
\cline { 2 - 3 } & 410 & 8400 \\
\hline 330 & 450 & 8100 \\
\hline
\end{tabular}

growth steps, thus giving rise to the formation of the macrosteps. Due to advancement of the macrosteps leads to the flat organic molecules are being built into the interplanar space of the growing crystal.

The AFM image of the influence of the impurity of thallium ions (Fig. 7d) differs sharply from the previous ones. The surface morphology of the faces is more distorted in comparison with that of the undoped crystal. One can see many growth hillocks and severely broken growth steps. Obviously, this is due to the fact that isovalent thallium ions should replace lithium ions, but in view of a significant difference in ionic radii $\left(r_{\mathrm{Li}}=0.65 \AA, r_{\mathrm{TI}}=1.33 \AA\right)$ the crystal lattice is essentially deformed, and a lot of dislocation outcrops are formed.

Optical properties of doped LDP crystals.

It is known that in neutral and weakly acidic aqueous solutions salicylic acid is appears as a mixture of the neutral form and anion ( $\mathrm{N}$ and $\mathrm{A}$ in Fig. 8). As shown in [19], the absorption bands at $\lambda_{\text {abs } 1}=303 \mathrm{~nm}$ and $\lambda_{\text {abs2 }}=296 \mathrm{~nm}$ observed in salicylic acid solution correspond to the neutral and anionic forms, respectively. As follows from the data presented, the maximum absorption band of the salicylate anion is shifted hypsochromically to the neutral form of the acid.

Each form has its own emission band (450 nm for $\mathrm{N}$ and $408 \mathrm{~nm}$ for $\mathrm{A}$ ) with the Stokes shifts of 10800 and $9300 \mathrm{~cm}^{-1}$, respectively. Large values of the latter testify to intramolecular proton transfer in the excited state in both forms. Thus, the fluorescent form corresponding to the neutral molecule of salicylic acid is its phototautomeric form $\mathrm{T}^{*}$. In the case of anion excitation, there is observed emission of anion-tautomeric form $\mathrm{AT}^{*}$ [19].

LDP crystal growth solutions have $\mathrm{pH}=$ 0.7 [8]. Under these conditions, only the neutral form of $\mathrm{H}_{2} \mathrm{Sal}$ is stable, which is confirmed by the presence of the corresponding $\mathrm{N}$ band in the absorption spectra

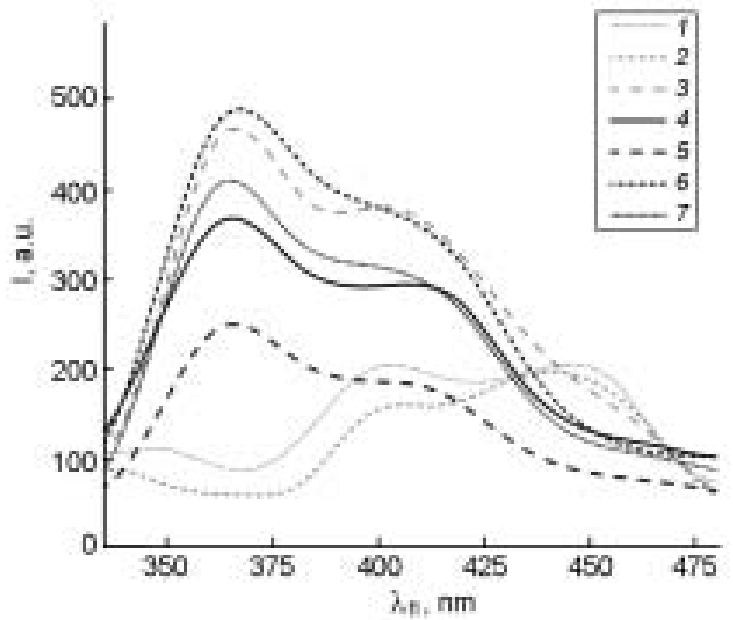

Fig. 9. Fluorescence anisotropy spectra of LDP: $\mathrm{H}_{2}$ Sal crystal rotated about the vertical axis by: 1) $\left.\left.-25^{\circ}, 2\right)-15^{\circ}, 3\right)-8^{\circ}$ (counter clockwise) and 4) $0^{\circ}$, 5) $\left.\left.8^{\circ}, 6\right) 15^{\circ}, 7\right) 25^{\circ}$ (clockwise) relative to the initial position of the crystal $\left(45^{\circ}\right.$ to the exciting beam).

and of the fluorescence band of the phototautomer $\mathrm{T}^{*}$.

In contrast to salicylic acid solutions, LDP crystals doped with salicylic acid show a three-band fluorescence with the maxima at $\lambda_{e m 1}=360 \mathrm{~nm}, \lambda_{e m 2}=410 \mathrm{~nm}$ and $\lambda_{\text {em } 3}$ $=450 \mathrm{~nm}$. Thereat, for all the emission bands, there is observed anisotropy of the emission intensity when the specimen is rotated about both the vertical axis (Fig. 9) and the horizontal axis (Fig. 10).

The fluorescence excitation spectra measured at $\lambda_{e m 1}=360 \mathrm{~nm}, \lambda_{e m 2}=410 \mathrm{~nm}$ and $\lambda_{\text {em3 }}=450 \mathrm{~nm}$, have maxima for $\lambda_{\text {ex1 }}=$ $305 \mathrm{~nm}, \lambda_{\text {ex2 }}=305 \mathrm{~nm}$ and $\lambda_{\text {ex3 }}=330 \mathrm{~nm}$, respectively. Thus, it can be concluded that the emission bands at 360 and $410 \mathrm{~nm}$ are associated with the absorption of the anionic form in the ground state, whereas the $450 \mathrm{~nm}$ band corresponds to the absorption of the neutral form. The Stokes shifts of the emission bands with $\lambda_{e m 2}=410 \mathrm{~nm}$ and $\lambda_{\text {em3 }}=450 \mathrm{~nm}$, calculated with respect to the corresponding bands in the fluorescence excitation spectra, have anomalously high values of 8400 and $8100 \mathrm{~cm}^{-1}$ (Table 2). This allows to assign the $\lambda_{e m 2}$ and $\lambda_{e m 3}$ bands to the emission of the corresponding photoautomeric forms $-A T^{*}$ and $\mathrm{T}^{*}$, respectively. The Stokes shift for the emission band with a maximum of $360 \mathrm{~nm}$ is small - $5000 \mathrm{~cm}^{-1}$, which allows attributing the latter to the emission of the original anionic form $\mathrm{A}^{*}$ (Fig. 8). 


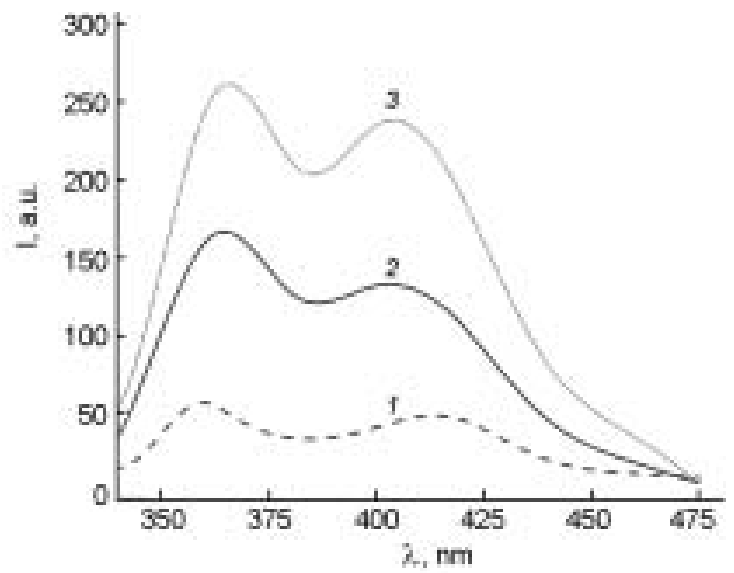

Fig. 10. Fluorescence anisotropy spectra of LDP: $\mathrm{H}_{2}$ Sal crystal rotated about the horizontal axis by: 1) $\left.35^{\circ}, 2\right) 0^{\circ}$ (clockwise) and 3 ) $-35^{\circ}$ (counter clockwise) relative to the initial position of the crystal $((\overline{1} 10)$ plane is parallel to the one formed by the incident and reflected beams).

The obtained spectral data make it possible to draw several conclusions about the state of salicylic acid in the crystalline phase. Even at high acidity of the solution, during the adsorption of $\mathrm{H}_{2} \mathrm{Sal}$ molecules on the crystal faces, their significant polarization occurs, leading to the dissociation of the neutral form of $\mathrm{N}$ and the formation of a monoanion A: $\mathrm{H}_{2} \mathrm{Sal} \rightarrow \mathrm{HSal}^{-}$. As in aqueous solutions, salicylic acid dissociates through the carboxylic group, so the intramolecular hydrogen bond between the orthohydroxylic group and the carboxylic group is not broken. As a result, the ability of the neutral and anionic forms to intramolecular proton transfer in the excited state is preserved.

The fluorescence of the anionic form of $\mathrm{A}^{*}$ can be observed only in the case of a significant deceleration or the absence of proton transfer in the excited state (ESIPT). Thereat, taking into account the barrierfree character of proton transfer in salicylates [20], the latter assumption seems more probable. Termination of the ESIPT is usually observed when the intramolecular hydrogen bond breaks down due to the formation of the rotamer of the anionic form $\mathrm{A}_{\mathrm{R}}^{*}$ [21], or if the anion forms intermolecular hydrogen bonds with molecules of a solvent or the crystal lattice $-\mathrm{A}_{\mathrm{H}}^{*}[22]$. Thus, the presence of a short-wave emission band can be explained by the formation of a population of $\mathrm{HSal}^{-}$anions which have an intermo- lecular hydrogen bond, for example, with phosphate anions in the crystal lattice $\mathrm{A}^{*}{ }_{\mathrm{H}}$ or/and the formation of the rotamers $\mathrm{A}_{\mathrm{R}}^{*}$ (Fig. 8).

Fluorescence anisotropy points to a certain orientation of various protolytic forms of salicylic acid in LDP: $\mathrm{H}_{2} \mathrm{Sal}$ crystals. When the crystal is rotated about the vertical axis from the $+25^{\circ}$ position to the $-25^{\circ}$ position, the intensity of the emission bands relating to the initial and phototautomeric form of the salicylate anion decreases symbatically, and the maximum of the integral fluorescence intensity corresponds to the $+15^{\circ}$ crystal position. With further rotation of the crystal towards the $-25^{\circ}$ position, the emission band belonging to the initial form of the salicylate anion $\left(\mathrm{A}_{\mathrm{H}}^{*}, \mathrm{~A}_{\mathrm{R}}^{*}\right)$ disappears, and there appears a band corresponding to the phototautomeric form of salicylic acid $\left(\mathrm{T}^{*}\right)$, and the maximum of integral fluorescence intensity corresponds to the position of the crystal $-15^{\circ}$.

The electronic structure of the molecules of salicylic acid and salicylate anion is such that the highest probability of their excitation is achieved in the case when the exciting light beam is directed perpendicular to the plane of the benzene ring (and, consequently, perpendicular to the planes of the molecules $\mathrm{N}$ and $\mathrm{A})$. Thus, the effect of fluorescence anisotropy can be used to analyze the location of neutral molecules and salicylic acid anions with respect to the planes of LDP crystal. Taking into account the relative orientation of the exciting beam with respect to the planes of $\mathrm{N}$ and $\mathrm{A}$, it can be concluded that the rotation of the sample by $+15^{\circ}$ and $-15^{\circ}$ relative to the initial position of the crystal corresponds to the position of the molecules at an angle of $30^{\circ}$ and $60^{\circ}$ to the plane $(110)$, respectively.

Proceeding from the model of spiral-layered growth of LDP crystals, one can assume that the elementary growth steps propagate on the growing plane (110); the height of these steps usually corresponds to the parameter of the unit cell of the crystal. The source of the steps is either the outcrop of a screw dislocation, or an edge separating two adjacent planes. In the most general form the influence of impurities on the propagation of the steps is described by the Cabrera-Vermilyea model [23], when the impurity is located on a terrace between the steps and slows down the progress of the step. The effect of nonisomorphic impurities can also be described by the said model, but in this case the impurities cannot replace 


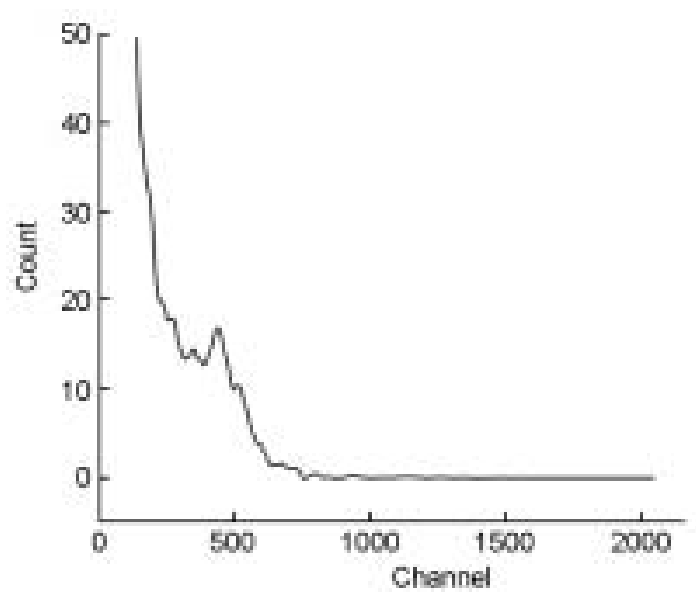

Fig. 11. Spectrum of registration of $\alpha$-particles formed due to thermal neutron capture in LDP crystal.

the crystal lattice atoms due to their incompatibility with the dimensions of the organic molecules. Nevertheless, planar molecules with dimensions less than the interplanar distances in the crystal can be located on the terrace between the steps and slow down the progress of the step. In this case, there are formed macrosteps that lock the molecule in the interplanar space inside the crystal. The observed effect of fluorescence anisotropy testifies that the arrangement of the molecule plane of salicylic acid derivatives close to $30^{\circ}$ and $60^{\circ}$ relatively to the (110) plane, when the molecules are incorporated into the crystal, occurs in the case when they are located at the ends of the growth steps that coincide with the planes (111) and (011), adjacent to the (110) plane. The angles between the planes (110) and (111), and between the planes (110) and (011) are $35.13^{\circ}$ and $64.99^{\circ}$, respectively (Fig. 2).

The emission spectrum of salicylic acid derivatives, located at an angle of $64.99^{\circ}$ relative to the (110) plane (Fig. 9, curve 2) points to the fact that in this case the phototautomeric forms of neutral salicylic acid $\mathrm{T}^{*}$ and of salicylate anion $\mathrm{AT}^{*}$ are present. Partial dissociation of salicylic acid molecules incorporated into the interplanar space of the crystal lattice can be due to an essential local polarity of the faces $\{111\}$, $\{201\},\{110\}$ and $\{011\}$, which terminate with alternating rows of dihydrogen phosphate anions and $\mathrm{LiO}_{4}$ tetrahedrons.

The emission spectra of salicylic acid derivatives located at an angle of $35.13^{\circ}$ relative to the (110) plane (Fig. 9, curve 6) testify that in this case there are arranged only the $\mathrm{HSal}^{-}$anions responsible for the appearance of fluorescence of the forms $\mathrm{A}_{\mathrm{H}(\mathrm{R})}{ }^{*}$ and $\mathrm{AT}^{*}$. Apparently, this is due to a greater local polarity of the $\{111\}$ faces on which dissociation of salicylic acid molecules occurs completely during embedding into the crystal. As noted above, the presence of the fluorescence band of the initial form of salicylate anion shows that some of the anions can turn into another rotameric form, or create intermolecular hydrogen bonds with dihydrogen phosphate anions of the faces $\{111\}$ during adsorption.

When the crystal is rotated about the horizontal axis from $+35^{\circ}$ to $-35^{\circ}$ (relative to the initial position of the crystal), there is observed an increase in the fluorescence intensity of the crystal, which confirms the previous conclusion about the arrangement of the molecular plane at the ends of the growth steps formed by the plane (011). Thus, in the case of the $+35^{\circ}$ position of the crystal, the angle between the exciting beam and the planes of salicylate anions coinciding with the (011) and (111) planes is $\sim 30^{\circ}$ and $\sim 60^{\circ}$, respectively, and at $-35^{\circ}$ this angle is $\sim 75^{\circ}$ and $\sim 100^{\circ}$, respectively, which increases the probability of excitation of $\mathrm{HSal}^{-}$and, correspondingly, the intensity of their emission.

Sensitivity of LDP crystals to thermal neutrons.

The KDP crystal was irradiated with a mixed flow of fast and thermal neutrons from a Pu-Be source, retarded by a layer of polyethylene with a thickness of $17.5 \mathrm{~cm}$. The signal was recorded using an $\alpha$-detector (Nal:Tl). To separate the signal from thermal neutrons, the sample was screened by a cadmium shield that absorbed thermal neutrons. The signal from the fast neutron flux was subtracted from the signal obtained from the mixed flux of fast and thermal neutrons ("cadmium difference"). Fig. 11 shows the spectrum of registration of $\alpha$ particles formed in LDP crystal due to the interaction of thermal neutrons with ${ }^{6} \mathrm{Li}$ isotope according to the reaction:

$$
\begin{gathered}
n+{ }^{6} \mathrm{Li}(7.5 \%) \rightarrow{ }^{3} \mathrm{H}(2.75 \mathrm{MeV})+4 \mathrm{He}(2.05 \mathrm{MeV}), \\
\sigma=940 \text { barn. }
\end{gathered}
$$

(The content of the ${ }^{6} \mathrm{Li}$ isotope in natural raw materials is $\sim 7.5 \%$ ).

Thus, LDP crystals grown with the isotope ${ }^{6} \mathrm{Li}$ may be used as a converter of thermal neutrons. 


\section{Conclusion}

Developed is a new approach to the growth of LDP crystals from viscous aqueous acid solutions, which involves meltgrowth techniques - a modified top-seeded solution growth. LDP single crystals with the orientation of the growth plane (110) are obtained.

It is established that as the concentration of acid in the solution increases, the habit of the crystals changes: the growth rate of the faces $\{110\}$ increases, the ratio of the areas of the faces changes toward an increase of the area of the pyramid $\{111\}$ and the pedestal $\{00 \Gamma\}$ plane area. That is due to the rise in the degree of association of the dihydrogen phosphate anions in the solution.

It is shown that the mechanism of the growth of LDP crystals is layered-spiral. The influence of the admixture of salicylic acid manifests itself in a decrease in the width of the terraces and an increase in the density of the growth steps thus causing the formation of macrosteps.

The fluorescence anisotropy points to the fact that the molecules of salicylic acid, built into the interplanar space of a growing crystal, are located at the ends of the growth steps, which coincide with the (111) and (011) planes adjacent to the (110) plane. The molecules while being embedded into the plane (011) and (111) undergo partial and complete dissociation, respectively, which may be due to a significant local polarity of the faces. Some of the anions can undergo transition into another rotameric form upon adsorption or form intermolecular hydrogen bonds with the dihydrogen phosphate anions of the [111] faces.

LDP crystals grown with the isotope ${ }^{6} \mathrm{Li}$ may be promising for the use in converters of thermal neutrons.

\section{References}

1. L.N.Rashkovich, KDP-family Single Crystals, Adam Hilger, Bristol (1991).

2. N.Zaitseva, L.Carman, Prog.Cryst. Growth Charact., 43, 1 (2001).

3. M.Catti, G.Ivaldi, Zeitschrift fur Kristallographie-Crystal. Mater., 146, 215 (1978).

4. K.-S.Lee, J.-H.Ko, J.Moon et al., Sol. State Commun., 145, 487 (2008).

5. L.V.Soboleva, I.L.Smolsky, Crystallogr. Reports, 42, 700 (1997).

6. S.Haussuhl, Cryst. Res.Techn., 31, 323 (1996).

7. K.-S.Lee, I.-H.Oh, J. J.Kweon et al., Mat. Chemi Phys., 136, 802 (2012).

8. A.P.Voronov, G.N.Babenko, A.N.Iurchenko et al., J. Cryst. Growth, 374, 49 (2013).

9. W.Kaminsky, J. Appl. Crystallogr., 38, 566 (2005).

10. D.Palmer, Yarnton, Oxfordshire, England (2009).

11. I.M.Bytieva, Cryst. Growth, 4, 22 (1964).

12. C.Sun, D.Xue, Rev. Adv. Sci. Engin., 1, 173 (2012).

13. D.A.Vorontsov, V.N.Portnov, V.P.Iershov, Abstr the 2-nd Intern. Conf. "Genesis of Crystals and Mineralogy", S.-Petersburg (2007), p.8.

14. V.Wazer, Interscience, New York, 1, 480 (1958).

15. A.N.Iurchenko, A.P.Voronov, G.N.Babenko et al., Functional Materials, 3, 325 (2014).

16. N.Zaitseva, J.Newby, G.Hull et al., Cryst. Growth Design, 9, 3799 (2009).

17. A.P.Voronov, V.B.Distanov, A.D.Roshal, $U k r$. J. Chem., 74, 36 (2008).

18. J.J.De Yoreo, A.Wierzbicki, P.M.Dove, Cryst. Eng. Commun., 9, 1144 (2007).

19. I.P.Pozdnyakov, A.Pigliucci, N.Tkachenko et al., J. Phys. Org. Chem., 22, 449 (2009).

20. A.Douhal, F.Lahmani, A.H.Zewail, J. Chem. Phys., 207, 477 (1996).

21. D.M.Friedrich, Z.Wang, A.G.Joly et al., $J$. Phys.Chem.A, 103, 9644 (1999).

22. G.S.Denisov, N.S.Golubev, V.M.Schreiber et al., J. Molec. Struct., 436-437, 153 (1997).

23. N.Cabrera, D.A.Vermilyea, Proceedings, Wiley, New York (1958), p.393. 